\title{
ФЕНОМЕН «ГОЛОЙ ЖИЗНИ» В КОНТЕКСТЕ КОНСТРУИРОВАНИЯ СМЕРТИ ЧЕЛОВЕКА
}

\begin{abstract}
Аннотация. В статье проводится аналогия между сущностными характеристиками пространства лагеря и палаты интенсивной терапии современной больницы. Лагерь рассматривается как биополитическая матрица современного мира, структура, порождающая феномен жизни, лищенной политической воли и права голоса («голой жизни» - в терминологии Дж. Агамбена. В статье исследуется, каким образом стратегия формирования "голой жизни» определяет этико-гносеологический формат отношения к пациенту с диагнозом "смерти мозга». Процесс конструирования отношения к смерти сопряжен с выстраиванием деонтологии умирания, соответствующей парадигме смерти, разделяемой сообществом. В технологически развитом мире она оказывается подключена к закону воспроизводства человеческих ресурсов и обмена социальными благами (донорства) Используется методология междисциплинарных исследований: анализ проблем современной медицины (в частности, проблем донорства и смерти мозга) проводится путем привлечения философского понятийно-категориального аппарата. В статье впервые в отечественной философии продемонстрировано влияние представлений о «голой жизни» на формирование дискурсивного поля и тезауруса современной философии сознания, а также показано, что настороженное отношение $к$ донорству и констатации смерти мозга вызывается воздействием различных культурных феноменов: художественной литературы, произведений кинематографии, изобразительного искусства и т.д. Они обращены к массовому читателю (зрителю), способствуя формированию общественного мнения относительно жизни и смерти и должны быть осмыслены, чтобы дать адекватные ответы на проблемы, волнующие массовое сознание.

Ключевые слова: психология умирания, биоэтика, человек как артефакт, умирание, смерть, конструирование человека, голая жизнь, конструирование смерти, смерть мозга, донорство.
\end{abstract}

реди различных дисциплинарных пространств (школ, больниц, тюрем), прекрасно описанных в работах М. Фуко, одно все же оказалось обойдено вниманием. Речь идет о лагере. Лагерь оказался обойден вниманием не случайно, ведь осмысление законов его функционирования и жизни «лагерного» субъекта, являет собой реконструкцию, которая бросает вызов обыденному здравому смыслу. Впрочем, это можно было бы утверждать и в отношении других дисциплинарных пространств, однако лишь в той мере, в какой они заключают в себе лагерь, являются его отражением. Возможно, лагерь и есть наша жизнь и задавая вопросы о лагерях, мы отворачиваемся от ответов, боясь в них обнаружить скрытые «лагерные» пружины нашей жизни, а в самих себе распознать предельно жестоких циничных надзирателей.
Проблема биополитического воздействия, проникающего в различные локусы жизни, поднятая и детально проанализированная М. Фуко, была подхвачена и рассмотрена в лагерном контексте итальянским философом Дж. Агамбеном. В работе «Homo sacer. Суверенная власть и голая жизнь» он называет лагерь биополитической парадигмой современности. Фактически за этим суждением о сущности лагеря скрывается то обстоятельство, что на фоне увеличения степеней свободы современного человека и тенденций развития морального прогресса (выражающихся хотя бы в таком факте, как глобализация доктрины прав человека) лагерь так и не стал анахронизмом. Наоборот, будучи «скрытой матрицей» и «номосом политического пространства», он приобретает новые формы выражения, захватывая и поглощая все новые

Статья подготовлена при финансовой поддержке РГНФ (грант № 12-33-01419). 
формы социальности, посягая на весь универсум существования.

В этой связи моя задача будет связана с попыткой рассмотрения, как определенные характеристики лагеря проникают в те или иные пространства социальной жизни, как лагерь метастазирует по пространству социума. В особенности же меня будет интересовать пространство больницы, точнее, не столько оно (как предмет рассмотрения М. Фуко), сколько ее зоны интенсивной терапии, где современные биотехнологии создают прецеденты удержания человеческого существа на грани жизни и смерти. Те зоны неопределенности, которые формируются не только амбивалентностью моральных норм и непроясненностью вопроса, где же должна проходить антропологическая граница, но прежде всего особой политической волей (даже если речь, казалось бы, идет всего лишь о политике здравоохранения).

Зададимся вопросом: каковы основные характеристики лагеря? И почему они могут быть применимы к современной больнице (палатам интенсивной терапии)? Для ответов на эти вопросы отчасти воспользуюсь точкой зрения Дж. Агамбена: лагерь является «чрезвычайным», «исключительным» пространством: «речь идет о части территории, вынесенной за пределы обычного правопорядка, но от этого не становящейся внеш-

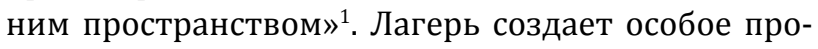
странство, где норма неотличима от исключения, где более того, само чрезвычайное положение оказывается нормой. Или, выражаясь другими словами, лагерь выступает структурой, где чрезвычайное положение осуществляется в нормальном режиме, а сама нормативность подвергается испытанию каждодневной абсурдностью существования. Однако, наиболее фундаментальной характеристикой лагеря является политизация голой жизни. Что же такое голая жизнь? И почему именно она становится предметом биополитики? Отвечая на этот вопрос, Дж. Агамбен следует взглядам М. Фуко, отметившем в работе «Воля к знанию», что с началом Нового времени политические стратегии направлены на человеческое тело. Причем это тело представлено в политических играх не только как субъект политики, но и как естественный объект, локус голой жизни, которой не дано право голоса (голая жизнь как бы исключена из

\footnotetext{
1 Агамбен Дж. Homo sacer. Суверенная власть и голая
} жизнь. М.: Европа, 2011. С. 211. политической сферы), но которое оказывает влияние на формирование политической воли. Голая жизнь является феноменом, который ускользает от схватывания в понятие субъекта, который лишен любой ауры трансцендентности. Как отмечает Дж. Агамбен, «Фундаментальной категориальной парой западной политики является не оппозиция друг/враг, а голая жизнь/политическое существование, zoe/bios, исключение/включение. Политика существует потому, что человек - живое существо, которое отделяет от себя и противопоставляет себе посредством языка свою собственную голую жизнь и в то же время остается связанным с ней через включающее исключение».

Противопоставление человека как живущего и говорящего берет свои истоки еще в античности. Однако именно современность и в особенности опыт мировых войн (в частности, концентрационных лагерей) проблематизировали эту дихотомию. Агамбен, ссылаясь на Антельма, подчеркивает, что то, «чему действительно концентрационные лагеря научили своих обитателей, это именно то, что «когда человеческое достоинство ставится под вопрос, это вызывает почти что биологическое отстаивание принадлежности к человеческому роду».

В концентрационных лагерях создается новый видживых существ, кого на лагерномжаргоне называют «мусульманами» ${ }^{2}$, тех, кто находился в особой онтологической зоне, где отсутствовала различенность природного/неприродного, кто олицетворяя голую жизнь, одновременно являлся продуктом политических технологий, отражением эксперимента над человеческой природой, взращенной в лагерных условиях ${ }^{3}$. Здесь человек уподобляется природному артефакту - лабораторному живот-

\footnotetext{
2 Сам термин «мусульманин» («Muselmann»), которым оперирует П. Леви, да и многие другие узники концлагерей (например, В. Франкл) был общим для всех немецких лагерей. Им называли ослабевшего, обреченного на смерть заключенного, испытывающего полное безразличие к окружающему миру и самому себе при абсолютной утрате норм культурного существования и опустошении внутренней жизни. Подробнее о «мусульманах» можно прочитать в работе: Агамбен Дж. Homo sacer. Что остается после Освенцима: архив и свидетель. М.: Европа, 2012.

3 Об использовании человеко-машин в советской лагерной системе см.: Тищенко П.Д. Вместо заключения. ГУЛАГ: модернизация и мегамашины по Льюису Мамфорду // Рабочие тетради по биоэтике Вып. 13: Человек - NBIC машина: исследование метафизических оснований инновационных антропотехнических проектов: сб. науч. ст. / Под ред. П.Д. Тищенко. М.: Изд-во Моск. гуманит. ун-та, 2012.
} 


\section{Философия и психология}

ному, выращенному исключительно в целях эксперимента или же являющемуся побочным результатом такого эксперимента, в результате которого проводилась операция по расчленению субъектности, отбрасыванию его в досубъектное состояние, отделяя в нем живущего от говорящего. И зачастую он мог себя считать человеком или оценивать других как человеческих существ лишь на основе общей видовой принадлежности. Все остальное, возвышенное, сложное, культурное было, казалось, безвозвратно утеряно. Оставалась лишь «нищета духа» и «голая жизнь». Между тем, аргумент на базе видовой принадлежности появляется вновь. Современный технологический виток порождает прецедент формирования новых способов самопонимания и новых возможностей моделирования идентичности. Аргументация на базисе видовой принадлежности затрагивает очень сложные в технологическую эпоху вопросы: «когда человек прекращает быть членом своего вида?», «собственно каковы рамки человеческого?». Более конкретное выражение вопрос приобретает в отношении прецедентов использования реанимационных технологий, например, таких: «являются ли искусственно поддерживаемое человеческое тело со смертью мозга или гипотетически поддерживаемое обезглавленное человеческое тело живыми членами человеческого вида или они лишь вещи, обладающие признаками жизни?».

\section{Феномен голой жизни: «неоморты» и «зомби»}

Реанимационное пространство современной больницы революционно как в отношении возможностей, заложенных в нем для спасения человеческих жизней, так и по той причине, что в нем реализуется новая аксиологическая (и биополитическая) программа современности. В его основании лежит акт порождения новых форм жизни, жизни на грани со смертью, жизни, которую легко спутать со смертью. И именно в этом отношении пространство больниц оказывается аналогичным пространству концентрационного лагеря: здесь политическая воля создает возможность конструирования и отбора живых существ под конкретные прагматические задачи (они могут носить, например, евгенический характер, как в случае проведения массового пренатального генетического скрининга, так и обладать компенсаторными чертами, как в случае использования органов пациентов с диагнозом смерти мозга для восстановления здоровья).
Рассмотрю конкретный пример, являющийся классическим для современной биоэтики. Речь идет о Карен Куинлан - женщине, очень долгое время находившейся в запредельной коме и поставившей под вопрос проблему границ жизни и смерти. Для истории современной биоэтики Карен Куинлан стала воплощением онтологического сдвига, который порожден развитием современных медицинских технологий. Её тело, поддерживаемое автоматическими устройствами интенсивной терапии, больше не является тем природным объектом, который имел тесную связь с личностью Карен Куинлан. Это объект, порожденный технологиями, артефакт, возникший как в контексте достижений современной медицины, которые стали средствами реализации целей для биополитики. Что представляет собой тело Карен Куинлан? Это «лишь анатомия в движении, совокупность функций, чьей целью больше не является жизнь организма. Ее жизнь поддерживается только вследствие техник реанимации и на основе правового решения; это уже не жизнь, а смерть в движении... тело Карен Куинлан, колеблющееся между жизнью и смертью в зависимости от прогресса медицины и принятия разных правовых решений, - это правовое бытие не в меньшей степени, чем бытие биологическое. Право, претендующее на решение о жизни, воплощается в жизнь, которая совпадает со смертью» 4 .

Тело Карен Куинлан демонстрирует феномен голой жизни - жизни, которая одновременно является и личностной, и политической драмой. Научное описание амбивалентности ее состояния, которое здравый смысл подменял простым вопросом: «что же с ней делать?», может быть спроецировано как на когорту пациентов, находящихся в коме, или тех, кому был поставлен диагноз смерти мозга, равно как и на любых других человеческих существ, у которых «гуманное» человеческое сообщество фиксирует те или иные отклонения от нормы: социальной, эстетической, генетической и т.д., и т.п. (в отношении этой темы диапазон человеческого воображения необычайно широк), считающиеся несовместимыми с жизнью, точнее, не дающими право на тот вариант жизни, на то ее выражение, которым они обладают. Следует подчеркнуть, что биополитические стратегии, обна-

4 Агамбен Дж. Нomo sacer. Суверенная власть и голая жизнь. M.: Европа, 2011. (URL: http://lib.vkarp.com/2013/10/19/ (дата обращения: 25.06.2014)). 
жающие феномен голой жизни, проявляются еще и на дискурсивном уровне, например, на уровне философской рефлексии. В интеллектуальных дебатах, в особенности, в философских прениях по проблемам сознания последних лет все чаще возникает фигура «зомби». «Зомби» - это абстракция, интеллектуальная конструкция, родившаяся в результате мысленных экспериментов, в основе которой лежит представление о существе, которое может иметь все признаки нормального человека, но не обладает сознательным опытом (квалиа) или ощущениями. В современной философии сознания реализовалась базовая интенция современной биополитики: отделять живущего от говорящего, от осознающего, от чувствующего. Зомби может имитировать некоторые признаки человеческого поведения, например, способность чувствовать боль, не обладая при этом внутренним опытом восприятия тех или иных модусов человеческого существования. Философия сознания населена различными видами зомби, которым приписываются различные характеристики. Например, когда речь идет, о таком типе «зомби», как неврологический, подчеркивается, что он, имея человеческий мозг, и будучи физически неотличим от человека, не обладает никаким сознательным опытом. Гипотетическая фигура зомби, своего рода абстракция от человека, родившаяся в мыслительном пространстве философии, абсолютно реальна в другом онтологическом измерении - современном пространстве отделения интенсивной терапии. Использование фигуры «зомби» в современных дискуссиях по философии сознания показательно с точки зрения того, как современный человек мыслит и производит самого себя с помощью биотехнологий, какие антропологические образы он допускает, пропустив через нормативный фильтр современной биополитики и общественного мнения. Эта фигура интересна еще и тем, что позволяет задуматься о том, какие образы собственной самости являются для нас чуждыми, что за типы существ отторгаются современными социокультурными практиками. Выявляется, что прежде всего отторжение происходит по критерию наличие/отсутствие сознания и тех или иных проявлений сознательной деятельности.

Приведу в этой связи яркую иллюстрацию ведущего представителя философии сознания Д. Деннета: «Тысячи философских мысленных экспериментов ... основывались на той идее, что я это не мое тело, но ... хозяин моего тела. В случае операции по пересадке сердца вы хотели бы быть реципиентом, а не донором, но в случае операции по пересадке мозга вы хотели бы быть донором, так как вы переходите с мозгом, а не с телом» 5 .

Деннет признает, что он (как, впрочем, и многие другие философы) следует проторенным путем картезианского дуализма.

В докладе Президентского совета по биоэтике США, посвященного обоснованию концепции смерти мозга 6 , картезианский дуализм проявляется в более завуалированной форме. Здесь обозначены базовые модальности человеческого бытия: открытость миру, то есть восприимчивость к стимулам и сигналам из окружающей среды, способность оказывать влияние на мир с целью удовлетворения собственных потребностей, базовой способности ощущения, дающей возможность организму действовать так, как он должен действовать и получать то, в чем он нуждается, и что его открытость делает возможным. Непроявленность этих модальностей означает смерть. За метафорой «открытости» скрывается такая характеристика, как отражение сознанием реальности. Этой характеристике придается императивное звучание.

Возвращаясь к фигуре «зомби», отмечу, что она интересна еще и в отношении того, как может строиться социальное пространство из существ, лишенных ментальности актом чьей-то мысли. Сконструированный мир, населенный такими существами, по своим внешним признакам уподобляется нашему миру, например, его существа по внешним проявлениям похожи на нас (они копируют наши действия), однако его внутреннее устройство абсолютно противоположное, социальность этого мира лишь кажущаяся: у обитателей этого мира полностью отсутствует чувствительность и восприятие своих собственных действий, например, они могут кричать от боли, но при этом не чувствуют ее. «Зомби» как некоторая абстракция (по некоторым признакам напоминающая абстрактного пациента с диагнозом смерти мозга) отсылает к фундаментальному биологическому основанию: той самой голой жизни, которая делает из узника концлагеря - лишенного способности чувствовать и переживать «мусульманина», а из пациента с диагнозом смерти мозга - «неоморта». Фено-

\footnotetext{
5 Деннет Д. Виды психики: на пути к пониманию сознания. М.: Идея-Пресс, 2004.

6 См.: Controversies in the Determination of Death. The President's Council on Bioethics. Washington: D.C., 2009.
} 


\section{Философия и психология}

мен зомби сконструирован мышлением, лишенным ориентации на целостность, оставляющим от полноты человеческого существа некоторые экстракты, трагично замещающие самого человека, формирующие из него новый вид существ. Это вид таких существ, чьи жизни уподобляются «homines sacri, жизни, которую можно было уничтожить, не совершая убийства» ${ }^{7}$, убить в рамках закона (под какими бы благовидными предлогами она не отбиралась - сохранения ли финансовых ресурсов здравоохранения для других категорий больных или на гуманном основании возможности продления жизни других людей). Как это осуществляется конкретно? С помощью ведущихся стратегических языковых игр. Во многих дискурсах о смерти мозга пациента с данным диагнозом описывается как биомашина, функционирующая благодаря ИВЛ, его также называют артефактом технологической поддержки, формой жизни, созданной медицинскими технологиями: его живое бытие оценивается как побочный эффект запуска реанимационными технологиями биомашины - человеческого тела. Онтологический статус пациентов в таких описаниях оказывается в чем-то ниже машинного и собственно машина (реанимационные технологии) рассматривается в качестве первоистока их бытия. Ее роль не ограничивается поддержанием жизни. Она фигурирует как вещь, продуцирующая новые формы жизни. Подобные описания носят исключительно прагматический характер. Например, особый лингвистический акцент на том, что процедура констатации факта смерти проводится в условиях, когда основные функции организма поддерживаются искусственно, позволяет снизить потенциальный риск конфликтных ситуаций между врачами и родственниками пациента, полагающими, что если у человека бьется сердце, то он жив. Период ожидания, во время которого происходит подтверждение диагноза смерти мозга, зачастую оказывается тем самым, выделенным Дж. Агамбеном, временным интервалом «между осуждением на смерть и исполнением приговора», внутри которого «человеческое тело утрачивает свой обычный политический статус и оказывается в ситуации исключения (чрезвычайного положения), где оно теперь ничем не защищено» ${ }^{8}$. В этом интервале осо-

\footnotetext{
7 Агамбен Дж. Ноmo sacer. Суверенная власть и голая жизнь. М.: Европа, 2011. (URL: http://lib.vkarp.com/2013/10/19/ (дата обращения: 25.06.2014)).

8 Там же.
}

бенно чётко представлена позиция врача, границы власти которого в хронотопе больницы отчасти совпадают с границами власти суверена, распоряжающегося правом на жизнь и на смерть. Врачу здесь делегировано право обладать высшей властью по сравнению с той, которую мог бы себе позволить суверен. Фактически и суверен мог бы стать тем, на кого распространялась бы эта власть - власть экспертов - «интеллектуалов» в области здравоохранения, нормирующих современное пространство медицины, создающих тот или иной аксиологический порядок, внутри которого конституируются те или иные императивы. Императив «не умри» - «во всяком случае, умри не как угодно, а только с дозволения закона и медицины» (Ж. Бодрийяр) определяет характер отношения к смерти как к артефакту. Он создан, с одной стороны, особой технической средой, дающей возможность пролонгирования жизни, с другой, особым отношением экспертов в области констатации смерти (врачей и юристов), определяющих момент наступления смерти, факт смерти как таковой, занимающихся научным конструированием смерти.

Появление в интеллектуальных дебатах таких абстракций, как «зомби», является индикатором необходимости уточнения понятия сознания. Человек, постигая особенности внешнего мира и выстраивая на основе знания его законов новые миры, так и не смог постичь законы своего сознания, и с трудом впускает в границы истинно человеческого такие представления о человеческом субъекте, которые противоречат норме человека как автономного рационального дееспособного субъекта.

Очень точным и важным в этой связи представляется высказывание Метцингера, отметившего, что человечество находится на доисторической фазе развития, имея ввиду не теоретическое знание и технологии, но феноменологическое знание и технологии (знание о сознании). Фундаментальным вопросом является тот, захотим ли мы использовать новое знание о природе сознания, чтобы изменить свое собственное мышление. Лучше быть кем-либо или быть никем? «У нас есть лучшие теории и лучшие компьютеры, почему мы не должны также иметь лучших феноменальных я?»9. Что значит иметь лучшее феноменальное Я? Одним из ответов мог бы быть тот, что это Я об-

\footnotetext{
9 Metzinger Thomas. Being no one: the self-model theory of subjectivity. Massachusetts Institute of Technology, 2003.
} 
ращенное на многообразие форм сознательной и бессознательной жизни, открытое этому многообразию и не стремящееся по законам математики вывести из него среднестатистическую норму.

Фигура пациента с диагнозом смерти мозга, или неоморта, как назвал их Уиллард Гейлин, вызывает ужас, она несет в себе монструозные черты: у неомортов легальный статус трупов и жизнь поддерживается в них лишь ради прагматической цели: пересадки органов. Фигура зомби демонстрирует такой же устрашающий образ тел, необходимый для мысленных экспериментов относительно пересадок сознания (пока еще гипотетических).

Фигуру зомби вполне можно считать продолжением и воплощением идеологии развития трансплантации - это также «пространство исключения, где голая жизнь предстает как таковая, впервые полностью контролируемая человеком и его технологиями» ${ }^{10}$, впервые необходимая в своем асоциальном статусе.

\section{«Голая жизнь» в художественной литературе, или о психологии восприятия донорства и диагноза смерти мозга}

Донорство и констатация смерти - это социокультурные феномены, с которыми связаны выработанные в границах той или иной культуры онтологические и гносеологические коннотации, различные акценты в отношении того, где проходят границы сознания/тела, живого/мертвого, личного/общественного и т.д., артикулирующие то или иное культурное «чувствование» практик дара (донорства) и понимания жизни и смерти. Восприятие новой парадигмы смерти (на основании диагноза смерти мозга) на протяжении последних нескольких десятилетий оказалось связано с определенными опасениями, мифами, предубеждениями социокультурного характера. В Российской Федерации их проявлением является отсутствие легитимных оснований для констатации смерти мозга у детей и, следовательно, развития детской трансплантологии. Как правило, в нашем обществе высокий уровень недоверия к развитию института трансплантологии, характерный для социокультурной ситуации Российской Федерации, связывается с распространением СМИ ложных слухов о

10 Агамбен Дж. Homo sacer. Суверенная власть и голая жизнь. М.: Европа, 2011. (URL:http://lib.vkarp.com/2013/10/19/ (дата обращения: 25.06.2014)). «черных рынках» трансплантации, вызывающих деформацию положительного отношения общества к донорству, а также к констатации смерти на основании диагноза смерти мозга. Между тем, настороженное отношение к донорству и констатации смерти мозга вызывается также распространением стереотипов о донорстве под воздействием различных культурных феноменов: художественной литературы, произведений кинематографии, изобразительного искусства и т.д. Они обращены к массовому читателю (зрителю), способствуя формированию общественного мнения относительно жизни и смерти и должны быть осмыслены, чтобы дать адекватные ответы на проблемы, волнующие массовое сознание.

На примере блестящего романа японского писателя Кадзио Исигуро «Не отпускай меня» можно продемонстрировать, как отражаются проблемы медикализированного технологического общества в современной прозе. Данное произведение можно считать выражением проблем медикализированного технологического общества. Здесь в художественной форме представлены социальные мифы и ожидания, связанные с проблемой донорства и отношения общества к категориям жизни и смерти.

Главная героиня романа делится воспоминаниями о некой школе, где в особо благоприятных условиях росли дети, призванные стать донорами. Доноры, о которых повествуется в романе, в глазах общества не являются людьми, они мертвы как социальные существа, поскольку у них не признается существования сознания/души. Они клонированы с целью изъятия у них органов и лишены любых других жизненных перспектив. Опираясь на сюжет книги, мне бы хотелось выявить заложенные в ней характерные установки относительно донорства органов и в свете них артикулировать в социокультурном ключе проблему смерти мозга.

1) Книга написана японским писателем, носителем японской ментальности.

Это имеет принципиальное значение, поскольку именно в Японии социокультурная составляющая диагноза смерти мозга особенно сильна. Японская модель донорства органов основана на плюрализме смерти (то есть человек может признавать и не признавать смерть на основании диагноза смерти мозга и если он не признает ее, то диагностика смерти мозга у него проводиться не будет - это свидетельствует о сомнении общества в «чистоте» диагноза смерти 
мозга и о настороженном отношении к донорству и трансплантации органов, и собственно поэтому, испытывая резкий недостаток органов, Япония осуществляет трансплантацию в США или в более дешевом варианте - в Китае, поток органов в который до недавних пор шел преимущественно из мест лишения свободы.

2) Проблема донорства от социально уязвимых, незащищенных групп населения.

Будущие доноры, жизнь которых описана в книге - это дети, растущие в особых приютах, своего рода детских домах. Они клонированы от преступных элементов общества (в романе упоминаются проститутки). Книга поднимает проблему существования «донорских» деревень (доноры после 18 лет живут в сельской местности - мы же можем вспомнить донорские деревни в Индии). В книге будущие доноры - это дети, растущие в особых приютах, своего рода детских домах. Они специально выращиваются, чтобы стать донорами. Тема потока донорских органов от уязвимых групп населения (детей, неопознанных лиц без определенного места жительства, заключенных, лиц, находящихся на территории военных действий) является актуальной для обсуждения во многих странах мира. Например, фобии относительно донорства в Российской Федерации проявляются в рассуждениях о возможности появления черного рынка донорских органов из детских домов, что влияет на формирование негативного отношения общества к развитию детской трансплантологии.

3) Проблема нравственного Ахиллеса, который никогда не догонит технологическую черепаху.

Книга поднимает проблему, которую условно можно было бы обозначить как проблему Ахиллеса, устремившегося за сверхскоростной черепахой. Ахиллес - это этическое знание, а черепаха - технический прогресс, темпы развития которого ускорялись и на определенном этапе приобрели скоростные характеристики, превышающие скорость Ахиллеса. Это прекрасно демонстрирует следующая цитата: «...когда одно за другим стремительно делались великие научные открытия, у людей не было времени критически все обдумать, поднять разумные вопросы... Внезапно открылась масса новых возможностей; многие болезни, с которыми врачи до тех пор не могли бороться, стали излечимыми... И люди долго предпочитали думать, что все эти человеческие органы являют- ся ниоткуда - ну, в лучшем случае выращиваются в каком-то вакууме ... к тому времени как люди начали беспокоиться из-за... воспитанников, к тому времени как их стало интересовать, в каких условиях вас растят и следует ли производить вас на свет вообще, уже было поздно... вас постарались упрятать подальше, и люди долго делали все возможное, чтобы поменьше о вас думать. А если все-таки думали, то пытались убедить себя, что вы не такие, как мы. Что вы не люди, а раз так, ваша судьба не слишком важна» ${ }^{11}$.

Хотя данное рассуждение касается прежде всего судьбы фантастических клонов-доноров, однако оно в равной степени может быть рассмотрено для анализа современного контекста проблемы донорства и констатации смерти мозга.

В книге поднимается проблема отсутствия времени для обсуждения этических проблем развития медицинских технологий. Развитие технологий требует принятия быстрых решений. Развитие идеологии донорства подавляет интерес публики к источнику происхождения органов, на первый план выдвигается идея спасения жизни. В трансплантологическом дискурсе позиция, выражающая какой-либо протест против концепции смерти как смерти мозга, рассматривается как аутсайдерская и даже этически ущербная. Дискурсы о смерти мозга являются индикаторами борьбы между дискурсами о человеке, закрепляющими за ним то роль личности, то функционально полезной для целей трансплантологии биомашины, функционирующей благодаря ИВЛ.

Книга К. Исигуро имела большой резонанс как за рубежом, так и в России, поэтому огромный интерес представляет анализ установок читателя в отношении проблемы донорства и трансплантации органов. Он может быть осуществлен на основе контент-анализа многочисленных читательских рецензий на книгу в сети Интернет, в полной мере характеризующих существующие предубеждения относительно донорства и констатации смерти мозга. Например, такая реплика, как «Человек жив, пока у него бьется сердце...» свидетельствует о существующих предубеждениях относительно неврологического критерия смерти (смерти мозга), а такая, как «Повернулся кран и на человечество полился дождь из превосходных здоровых органов и зачем думать о том, откуда эти органы, кто ими

11 Исигуро К. Не отпускай меня. М.: Эксмо, 2006. (URL: http://www.booksreader.org (дата обращения: 25.06.2014)). 


\section{Психология и психотехника 8(71) • 2014}

поделился, удобно не думать об этом и принимать, как должное» ${ }^{12}$, указывает на наличие опасений относительно «черного» донорства и т.д.

Итак, в современном мире процесс умирания и отношения к смерти конструируется и контролируется в соответствии с социально-экономическими задачами, стоящими перед обществом. Процесс конструирования отношения к смерти сопряжен с выстраиванием деонтологии умирания, соответствующей парадигме смерти, разделяемой сообществом. В технологически развитом мире она оказывается подключена к закону воспроизводства человеческих ресурсов и обмена социальными благами (донорства) ${ }^{13}$.

\section{Список литературы:}

1. Агамбен Дж. Ноmo sacer. Суверенная власть и голая жизнь. М.: Европа, 2011.

2. Гуревич П.С. Специфика антропологического знания // Философия и культура. 2014 . № 1. С. 7-11. (DOI: 10.7256/1999-2793.2014.1.10295).

3. Деннет Д. Виды психики: на пути к пониманию сознания. М.: Идея-Пресс, 2004.

4. Иванюшкин А.Я., Попова О.В. Проблема смерти мозга в дискурсе биоэтики. M.: Nota Bene, 2013.

5. Исигуро К. Не отпускай меня. М.: Эксмо, 2006. (URL: http://www.booksreader.org (дата обращения: 25.06.2014)).

6. Разин А.В. Тело человека как антропологический констант его общественного бытия // Философия и культура. 2011. № 10. С. 23-32.

7. Спирова Э.М. Символика жизни и смерти // Психология и психотехника. 2010. № 5. С. 75-82.

8. Тищенко П.Д. Вместо заключения. ГУЛАГ: модернизация и мегамашины по Льюису Мамфорду // Рабочие тетради по биоэтике Вып. 13: Человек - NBIC машина: исследование метафизических оснований инновационных антропотехнических проектов: сб. науч. ст. / Под ред. П.Д. Тищенко. М.: Изд-во Моск. гуманит. ун-та, 2012.

9. Controversies in the Determination of Death. The President's Council on Bioethics. Washington: D.C., 2009.

10. Metzinger Thomas. Being no one: the self-model theory of subjectivity. Massachusetts Institute of Technology, 2003.

\section{References (transliteration):}

1. Agamben Dzh. Homo sacer. Suverennaya vlast' i golaya zhizn'. M.: Evropa, 2011.

2. Gurevich P.S. Spetsifika antropologicheskogo znaniya // Filosofiya i kul'tura. 2014. № 1. S. 7-11. (DOI: 10.7256/1999-2793.2014.1.10295).

3. Dennet D. Vidy psikhiki: na puti k ponimaniyu soznaniya. M.: Ideya-Press, 2004.

4. Ivanyushkin A.Ya., Popova O.V. Problema smerti mozga v diskurse bioetiki. M.: Nota Bene, 2013.

5. Isiguro K. Ne otpuskai menya. M.: Eksmo, 2006. (URL: http://www.booksreader.org (data obrashcheniya: 25.06.2014)).

6. Razin A.V. Telo cheloveka kak antropologicheskii konstant ego obshchestvennogo bytiya // Filosofiya i kul'tura. 2011. № 10. S. 23-32.

7. Spirova E.M. Simvolika zhizni i smerti // Psikhologiya i psikhotekhnika. 2010. № 5. S. 75-82.

8. Tishchenko P.D. Vmesto zaklyucheniya. GULAG: modernizatsiya i megamashiny po L'yuisu Mamfordu // Rabochie tetradi po bioetike Vyp. 13: Chelovek - NBIC mashina: issledovanie metafizicheskikh osnovanii innovatsionnykh antropotekhnicheskikh proektov: sb. nauch. st. / Pod red. P.D. Tishchenko. M.: Izd-vo Mosk. gumanit. un-ta, 2012.

9. Controversies in the Determination of Death. The President's Council on Bioethics. Washington: D.C., 2009.

10. Metzinger Thomas. Being no one: the self-model theory of subjectivity. Massachusetts Institute of Technology, 2003.

12 URL: http://www.livelib.ru/book/1000326508/reviews (дата обращения: 25.06.2014).
13 Более подробно см.: Иванюшкин А.Я., Попова О.В. Проблема смерти мозга в дискурсе биоэтики. M.: Nota Bene, 2013. 